\title{
Mid-Crustal Focused Fluid Movement: Thermal Consequences and Silica Transport
}

\author{
J. A. D. Connolly \\ Institute for Mineralogy and Petrography \\ Swiss Federal Institute of Technology \\ Zurich CH-8092
}

\begin{abstract}
Numerical models have been constructed to assess the thermal consequences and silica transport that would result if water released by regional metamorphic dehydration or cooling plutons were focused into large-scale $(10 \mathrm{~km})$ fracture zones. Two fracture zone model geometries have been considered, in one the fracture zone is planar, and in the other the fracture zone is radially symmetric. In both models dispersion and collection of fluids is simulated.

The model results indicate that for planar or radially symmetric fracture zones, hydrothermal flow rates must approach $0.1 \mathrm{~g} / \mathrm{s}$ (per m crack length) or 1 $\mathrm{kg} / \mathrm{s}$, respectively, to produce significant thermal effects. Given that regional metamorphic fluid fluxes are probably $<10^{-9} \mathrm{~kg} / \mathrm{m}^{2}-\mathrm{s}$, generation of a thermal anomaly by fluids released during metamorphic dehydration into a planar fracture zone requires an unrealistic degree of lateral flow $(>50 \mathrm{~km})$. The collection area required to produce a detectable heating effect about a radially symmetric fracture zone is smaller (a radius of $\approx 15 \mathrm{~km}$ ), but also implausibly large. These scales suggest that focusing of fluids produced by regional dehydration processes will have negligible
\end{abstract}




\section{- ii -}

influence on the thermal development of metamorphic systems.

Granitic plutons, which may release $>3$ wt $\%$ water over a $50 \mathrm{~K}$ interval above their solidii, are potentially an important local source of fluid. For example, a tonalitic pluton, with a radius of $3.25-5 \mathrm{~km}$, emplaced at a depth of $20 \mathrm{~km}$ may release water at an average rate of $13-20 \mathrm{~kg} / \mathrm{s}$ for a period of $>25 \mathrm{ka}$. These rates are high enough that if the water is focused into a fracture zone, the flow is nearly isothermal and results in a transient heating effect raising temperatures $>200 \mathrm{~K}$ in rocks $10 \mathrm{~km}$ above the pluton.

None of the channelized flow models appear to provide an effective mechanism for producing pervasive quartz veining, but the very high fluid fluxes generated by plutons are capable of producing extensive silicification (>4 vol \%) within the vertical portion of a fracture zone, similar to that found in stock-work ore deposits. In the case of fluids produced by high temperature dehydration, more silica is precipitated at depth during focusing (>1 vol \%) and within the fracture zones than is precipitated during dispersion $(<0.2 \mathrm{vol} \%)$. This reflects both the relatively high rate of change in silica solubility with decompression at depth, and the low solubility at the shallower conditions.

April 24, 1996 


\title{
Mid-Crustal Focused Fluid Movement: Thermal Consequences and Silica Transport
}

\author{
J. A. D. Connolly \\ Institute for Mineralogy and Petrography \\ Swiss Federal Institute of Technology \\ Zurich CH-8092
}

\section{INTRODUCTION}

Petrologic evidence indicates that a fluid phase is almost invariably present during metamorphic activity. This association has led some petrologists to conclude that fluids are, at least sometimes, a source of metamorphic heat. An alternative view is that the association of fluids and metamorphic activity reflects the catalytic, rather than causal, role of fluids in metamorphism. This latter view is supported by numerical modeling of crustal metamorphism which suggests that regional scale metamorphic fluid fluxes, estimated to be on the order of $10^{-8}-10^{-10} \mathrm{~kg} / \mathrm{m}^{2}-\mathrm{s}$, are too small to significantly alter the thermal development of metamorphic systems (e.g., Peacock 1987, 1989; Brady 1989; Connolly \& Thompson 1989; Jamtveit et al. 1990). Thus, it appears that anomalously large fluxes are required to generate notable thermal effects. Such large fluxes may be attained if mantle sources comprise a major component of metamorphic fluid budgets (e.g., Schuiling \& Kreulen 1978, Ganguly et al. 1995), but the fluid compositions in this case are likely to be atypical of crustal metamorphism. This study examines the hypothesis that large scale fracture systems are capable of generating fluid fluxes adequate to cause localized heating at crustal depths $(>10-12 \mathrm{~km})$ where free-convection is unlikely. Such fracture systems have been hypothesized to explain "metamorphic hot spots" in New England (Chamberlain \& Rumble 1988), where metamorphic rocks apparently show evidence of heating independently of any regional or magmatic source. 
The thermal consequences of channelized fluid flow in two-dimensional parallel fractures have been examined in detail by Brady (1989) and Hoisch (1991) who present numerical and analytic solutions for the thermal profile about fluid channels. Brady's work has a number of interesting implications, perhaps the most important of which is that even accepting high estimates for regional fluid fluxes, metamorphic fluids must be focused into widely spaced channels (separated by $>2 \mathrm{~km}$ ) to raise the temperature of the rocks in the vicinity of the channel more than $10 \mathrm{~K}$ above the interchannel rock temperature. Brady's analytic solutions also show that given a constant total flux (i.e., integrated over channel width), variation in channel width has little effect on the temperature distribution around the channel provided this width is small $(\leq 10 \%)$ in comparison to the channel spacing. This is useful because it means that it is not necessary to understand the details of fluid flow, i.e., whether the flow is focused into a single conduit or it is spread out over a broad fracture zone, assuming local thermal equilibrium is maintained.

For fracture fluid flow to be an effective heat transfer mechanism, hot fluids must be focused into a fracture zone at depth, channeled upwards, and dispersed in cool shallower rocks. The process of dispersion is important for two reasons; it acts as a "thermal brake" that allows the fluid to cool rapidly; and it could explain pervasive veining and reequilibration which would otherwise not be expected. This study extends Brady's and Hoisch's analyses to account for these processes, and in many ways parallels the treatment by Pederson et al. (this volume) of fracture confined flow in sedimentary basins. In addition, radially symmetric focusing and mid-crustal granitic plutonism are considered here. These processes are potentially more effective mechanisms for generating high fluid fluxes than the channeling of fluid from regional devolatilization into planar fractures as discussed by Brady (1989). Silica transport through deep crustal fracture zones have also been proposed as a means of explaining pervasive quartz vein formation (e.g., Yardley 1986, Walther \& Orville 1982), and the models employed here can be used to test this hypothesis.

It has been recognized for some time that high fluid fluxes can be generated by free-convection around shallow cooling plutons (Norton \& Knight 1977). Whether free-convection occurs at greater depths is more controversial, it will depend on the degree to which connected porosity or fracture 
networks can be maintained, and therefore on rheology. Rocks at depths of greater than $10 \mathrm{~km}$ are likely to be too plastic during prograde metamorphism to allow large scale free-convection. In the absence of fracture networks, permeability variation resulting from lithological heterogeneity will further impede free-convection (Byorrlike et al. 1988). Thus it is unlikely that free-convection at depth can be very effective heat transfer mechanism, moreover the heating effect of free-convection would be diffuse and difficult to recognize. For these reasons, free-convection is not considered here. It is noteworthy though, that small scale free-convection cells as suggested by Etheridge et al (1983, cf. Connolly \& Ko 1995) could be a mechanism for producing pervasive quartz veining, which is difficult to explain on the basis of one-pass fluid flow models (Yardley 1986, Connolly \& Thompson 1989).

The present study, as those of Brady (1989) and Hoisch (1991), evaluates the effects of focused fluid flow, without considering the more fundamental question of how focusing may arise. Matthai \& Roberts and Thompson address aspects of this question in this volume.

\section{Focused Regional Metamorphic Fluid}

There is considerable evidence for fracture channelization of fluids released by metamorphic devolatilization on a scale of 0.1-1 km (e.g., Oliver et al. 1993); and Skelton et al. (1995) have demonstrated a fourfold increase in integrated fluid fluxes that occurred in response to lateral focusing of metamorphic fluid over distances approaching $10 \mathrm{~km}$ by an antiformal structure. Unfortunately, there is little, if any, direct evidence of the scale or geometry of fluid channels associated with thermal anomalies, except at shallow levels in the crust (e.g., Mikucki \& Heinrich 1993). However, if the "metamorphic hot spots" of Chamberlain \& Rumble (1988) are indeed the result of fluid channeling then they provide a number of constraints on the process of their formation. In the case they describe in detail, the Bristol hotspot, Chamberlain \& Rumble estimate that the hotspot formed at a depth of ca $12 \mathrm{~km}$ and raised the rock temperatures to about $973 \mathrm{~K}$, ca $300 \mathrm{~K}$ above the background temperature of $673 \mathrm{~K}$. This implies a normal geothermal gradient of $33 \mathrm{~K} / \mathrm{km}$, and, if the fluids were generated by dehydration, a minimum depth of the fluid source of ca $22 \mathrm{~km}$. The Bristol 
hotspot is roughly $6 \times 10 \mathrm{~km}$ in map section and evidence of hydrothermal activity (veins and isotopic reequilibration) is present throughout, suggesting that the fluids were dispersed throughout the hotspot.

\subsection{Regional Metamorphic Fluid Flux}

If the source of the fluids responsible for Bristol hotspot was water released by dehydration, the dehydration must have occurred at temperatures in excess of $973 \mathrm{~K}$ and at pressures of greater than 8 kbar*. Ignoring the difficulty of producing free water at these conditions in sialic material, a possible water source would be biotite dehydration. An estimate of the upper limit of fluid production by such a reaction can be obtained by assuming a (high) biotite mode of about 25 wt $\%$ combined this with a rapid rate of isograd advance, for a high temperature reaction, of $4 \times 10^{-11} \mathrm{~m} / \mathrm{s}(1.3$ km/Ma, e.g., Thompson 1989, Connolly \& Thompson 1989), this yields a flux of $10^{-9} \mathrm{~kg} / \mathrm{m}^{2}-\mathrm{s}$, designated here $\mathrm{q}^{*}$. Real fluxes are likely to be highly variable, but generally smaller, as most hydroxylated silicates, notably amphibole, contain less water. For comparison, most authors have estimated regional fluid fluxes less conservatively to be on the order of $10 \mathrm{q} *$ (Walther \& Orville 1982, Peacock 1989, Brady 1989), whereas Connolly \& Thompson (1989) suggested average metamorphic fluxes of $<0.2 \mathrm{q}^{*}$. From field evidence, Skelton et al. (1995) estimated the unfocused regional integrated fluxes to be on the order of $10^{5} \mathrm{~kg} / \mathrm{m}^{2}$, this integrated flux would be realized at $\mathrm{q}^{*}$ in ca $3 \mathrm{Ma}$, a relatively short time in the context of regional metamorphism.

Similar fluxes are derived given the assumption that the time scale of whole-crustal metamorphism is ultimately determined by heat conduction (England \& Thompson 1984). In this case the metamorphic time scale is:

$$
\tau_{\mathrm{M}} \approx \frac{1_{\mathrm{c}}^{2}}{2} \kappa
$$

*Chamberlain \& Rumble (1988) estimated metamorphic temperatures from the garnet-biotite geothermometer, differences in the calibrations of this geothermometer suggest the possibility of considerable systematic error in its use. Thus it may be more important to consider the reported temperatures differences, rather than the absolute temperatures. Systematically lower temperatures, would require less extreme conditions for fluid generation, but would not otherwise substantially effect the model results presented here. 
where $l_{c}$ and $\kappa$ are the crustal thickness and thermal diffusivity (Table 1 ). If the weight fraction of volatiles lost from the metamorphic pile is $X_{v}$, then the time-averaged fluid flux is:

$$
\hat{\mathrm{q}}=\frac{1_{\mathrm{c}} \Delta \mathrm{v}}{\tau_{\mathrm{M}}}=\frac{\mathrm{X}_{\mathrm{v}} 2 \kappa}{1_{\mathrm{c}}} .
$$

Pelitic crust loses about $3 \mathrm{wt} \%$ volatiles in the transition from lower greenschist to granulite facies (Fyfe et al. 1995). Thus for crustal thicknesses characteristic of extensional (10 km), thermal (35 $\mathrm{km})$, and collision belt metamorphism $(70 \mathrm{~km}), \hat{\mathrm{q}}=2-8 \times 10^{-9} \mathrm{~kg} / \mathrm{m}^{2}-\mathrm{s}$. This time-averaged flux would be obtained at the top of the metamorphic pile, consequently average fluxes deeper within the pile could be substantially lower (cf Connolly \& Thompson 1989). It is interesting to observe that if fluid pressure during metamorphism is near lithostatic, as inferred from phase equilibria (e.g., Fyfe et al 1978) rearrangement of Darcy's law:

$$
k_{h}=\hat{q}\left[\frac{\mu_{f}}{\rho_{\mathrm{f}} g \Delta \rho}\right]
$$

requires metamorphic permeabilities to be on the order of $10^{-20} \mathrm{~m}^{2}$. In Eq $3 \mu_{\mathrm{f}}$ is the fluid viscosity ( $10^{-4} \mathrm{~Pa}-\mathrm{s}$, Walther \& Orville 1982$), \Delta \rho$ is the difference between the fluid and rock density $\left(2 \times 10^{3}\right.$ $\mathrm{kg} / \mathrm{m}^{3}$ ), and $\mathrm{g} \Delta \rho$ is the pieziometric gradient.

For the distance scales $\mathrm{h} \approx 10 \mathrm{~km}$ considered here a minimum estimate of the focusing necessary for significant heat convection can be estimated by determining conditions such that thermal Peclet number:

$$
\mathrm{Pe}=\frac{\mathrm{hq}}{\rho_{\mathrm{f}} \kappa}
$$

for one-dimensional flow is of order 1 (Bickle \& McKenzie 1987). This approach yields focusing factors of order 100 for a regional flux of $\mathrm{q}^{*}$, but is likely to significantly underestimate the actual focusing required in the limit that the fracture zone is narrow $(<50 \mathrm{~m})$ because the fracture system then loses a substantial amount of heat by conduction to the wall rocks. 


\subsection{Fluid Focusing and Dispersion}

The models illustrated in Fig 1 have been adopted to simulate the collection and dispersion of fluid produced along a metamorphic dehydration reaction front into a planar or radially symmetric fracture zone. For brevity these models are referred to as "crack" and "pipe" flow models. In both models, fluids at depth are collected from a horizontal region (i.e., a dehydration reaction front). Once collected within this region (of width $\pm \mathrm{W}$ at depth $\mathrm{Y}_{\mathrm{f}}$, Fig 1) the fluid is gradually focused into the fracture within the inverted trough or cone shaped region truncated by the base of vertical fracture zone $\left( \pm \mathrm{w}\right.$ at $\left.\mathrm{Y}_{\mathrm{b}}\right)$. At any point within this region, except along the axis of the fracture zone, the flux will have a lateral component, fluxes outside this region are assumed to have no lateral component.

The efficiency of fluid catchment would be expected to vary with lateral distance from the fracture zone axis, being unity directly below the fracture zone, and decreasing asymptotically away from the zone. Because low fluxes are unimportant in heat and mass transport, this distribution can be represented by the catchment efficiency, E, where:

$$
\mathrm{E}=\cos \left[\frac{\pi \mathrm{r}}{2 \mathrm{~W}}\right]
$$

where $r$ is the lateral distance from the fracture zone axis. Eq 1 yields an efficiency of 1 at $r=0$ and nil at $r= \pm W$. Integrating Eq 1 over the entire width of the catchment zone yields total catchment efficiencies, $\hat{E}$, of $63.7 \%\left(\frac{2}{\pi}\right)$ and $46.3 \%\left(\frac{4}{\pi}\left[1-\frac{2}{\pi}\right]\right)$, for the crack and pipe model symmetries, respectively. The vertical $\left(\mathrm{q}_{\mathrm{y}}\right)$ and horizontal $\left(\mathrm{q}_{\mathrm{r}}\right)$ steady state flux components consistent with these assumptions within the focusing region are then:

$$
\mathrm{q}_{\mathrm{y}}=\mathrm{A} \cos \left[\frac{\pi \mathrm{r}}{2 \mathrm{u}}\right]
$$

and

$$
\mathrm{q}_{\mathrm{r}}=\mathrm{A} \frac{\mathrm{r}}{\delta \mathrm{y}} \cos \left[\frac{\pi \mathrm{r}}{2 \mathrm{u}}\right]
$$


where $\delta \mathrm{y}=\mathrm{y}-\mathrm{Y}_{\mathrm{b}}$ and $\mathrm{u}$ is the width of the focusing region at depth $\mathrm{y}$, i.e., $\mathrm{u}=\mathrm{W} \delta \mathrm{y} /\left(\mathrm{Y}_{\mathrm{f}}-\mathrm{Y}_{\mathrm{b}}\right)$.

The parameter A in Eqs 6 \& 7 is model dependent, for a planar fracture zone:

$$
\mathrm{A}=\frac{\mathrm{Q} \pi}{4 \mathrm{u}}
$$

where $\mathrm{Q}$, the total vertical flow rate through the fracture zone, is:

$$
\mathrm{Q}=2 \mathrm{~W} \hat{\mathrm{E}} \mathrm{q}
$$

For a radially symmetric fracture zone:

$$
A=\frac{Q}{\left.1-\frac{2}{\pi}\right] 4 u^{2}}
$$

and

$$
\mathrm{Q}=\pi \mathrm{W}^{2} \hat{\mathrm{E}} \mathrm{q} .
$$

The dispersion process is assumed to be the inverse of collection, applying Eqs 6 \& 7 with the appropriate modification. The component of the regional flux that is not focused is ignored. This component is small in comparison to the fluxes obtained for any significant focusing, and so may be discounted without important consequences.

Although Eq 5 is arbitrary, it is probably not a large component of the uncertainty in the models. The parameters chosen to describe the shape of the focusing and dispersion regions are more important. In the limit that all fluid produced along a reaction front flows laterally into a fracture zone, the focusing process will be isothermal and results in the highest possible fluid temperatures within the vertical fracture zone. Indirect evidence for bedding plane channeling of fluids within dehydrating rock has been observed (e.g., Ferry 1987, Skelton et al. 1995) for rocks metamorphosed at crustal depths $>12 \mathrm{~km}$. It is difficult to extract flux components from these studies, but strong lateral channeling in the lower crust would require large permeability contrasts and lateral fluid pressure gradients. Lateral fluid pressure gradients can be maintained only if rock viscosity is low, but at the high temperature-pressure conditions necessary to produce fluids capable of generating a metamorphic hotspots rocks are likely to deform rapidly. In view of this, it is assumed here 
that the lateral flux component is generally smaller than the vertical component.

The width of fluid focusing regions is difficult to constrain, a maximum width is given by the spacing of Chamberlain \& Rumble's (1988) hot spots. This width, ca $25 \mathrm{~km}$, is inconsistent with the assumption that the lateral flux components are smaller than the vertical flux components. In contrast, to the focusing problem, the width of the dispersion region is defined by Chamberlain \& Rumble's hotspots by the extent of hydrothermal veining. This veining extends over an area of about $10 \mathrm{~km}^{2}$ and indicates a minimum dispersion region width of $3 \mathrm{~km}$. In most of the model results presented here, a $5 \mathrm{~km}$ width (W) for the dispersion region is assumed, and for the sake of simplicity the same width is used for the focusing region. The effect of larger widths for the focusing region will be simulated by increasing the value of the regional flux. For example, focusing with $\mathrm{W}=5 \mathrm{~km}$ and $\mathrm{q}=10 \mathrm{q}^{*}$ is roughly equivalent to $\mathrm{W}=50 \mathrm{~km}$ and $\mathrm{q}=\mathrm{q}^{*}$ for a planar fracture model (Eq 9), or $\mathrm{W}=15 \mathrm{~km}$ and $\mathrm{q}=\mathrm{q}^{*}$ for radially symmetric flow (Eq 11).

Brady's (1989) equations show that the effect of the width of the fracture zone is relatively minor (see also below), thus unless otherwise noted a constant width of $500 \mathrm{~m}$ is used here (i.e., $\mathrm{w}=$ $250 \mathrm{~m})$.

\subsection{Solution of the Energy Conservation Equation}

The heat transfer coefficient for fluid-rock heat transfer (Ozisik 1985) is unlikely to differ significantly from unity for plausible fracture widths (e.g., Norton \& Knapp 1970). It follows that true adiabatic fluid flow can be excluded from consideration; therefore, only equilibrium heat flow models are applied here. The thermal consequences of focused steady state fluid flow were calculated by solving the energy conservation equation:

$$
\mathrm{C}_{\mathrm{rx}} \frac{\mathrm{dT}}{\mathrm{dt}}=\mathrm{k}\left[\nabla^{2} \mathrm{~T}+\frac{\mathrm{p}}{\mathrm{r}}\left[\frac{\partial \mathrm{T}}{\partial \mathrm{r}}\right]\right]-\mathrm{C}_{\mathrm{f}} \mathrm{q} \nabla \mathrm{T}
$$

where $\mathrm{p}$ is zero and one for the planar and radial symmetries, respectively (see Table 1 for symbols and parameter values). Stable numeric solutions of Eq 12 are difficult to obtain by standard finite difference techniques because of strong spatial variations in the model fluid fluxes and high Courant 
numbers. The techniques employed to circumvent these problems are described in the Appendix.

Constant temperature boundary conditions were assigned for horizontal boundaries the vertical boundaries of radially symmetric models. No-flow (mirror symmetry) conditions were used for the planar fracture models. In solving Eq 12, the movement of the reaction front and other effects of dehydration (enthalpy, compaction, mass loss, etc.) were ignored. This is justified given the relatively short time scale for the formation of advected heat anomalies $\left(\approx 10^{4} a\right)$ in comparison to that for reaction effects (Connolly \& Thompson 1989). Furthermore, because regional metamorphic dehydration rates are likely to be controlled by heat flow and therefore near equilibrium (e.g., Yardley 1986), the dehydration process will be essentially isothermal, as modeled here, regardless of endothermic dehydration effects. Variation in the conductivity, density, and specific heats of the fluid and rock due to temperature or fluid/rock proportions were not considered, these effects are small and would be difficult to evaluate precisely. Accuracy of the numerical solutions was tested by evaluating the energy conservation constraints, and by changing the node spacings employed. For all accepted solutions the instantaneous and cumulative energy conservation constraints were satisfied to within a tolerance of $0.1 \%$ of the energy transfer.

\subsection{Silica Precipitation and Throttling Effects}

To estimate the amount of silica transported and precipitated by focusing of metamorphic fluid, the fluid was assumed to be essentially pure water and saturated with respect to quartz. The equilibrium rate of quartz precipitation, $\dot{\mathrm{s}}$, was computed from

$$
\dot{\mathrm{s}}=\mathrm{q}_{\text {local }} \nabla \mathrm{C}
$$

where $\nabla C$ is the gradient in silica solubility due to variation in pressure and temperature, and $\mathrm{q}_{\text {local }}$ is the local fluid flux. Silica solubilities (Fig 2) were computed after Manning (1994), with water densities calculated using a modified Redlich-Kwong type equation. Pederson et al. (this volume) suggest a dis-equilibrium mechanism for advective silica transport in sedimentary basins, however such mechanisms are unlikely to operate in metamorphic systems because effective above ca $573 \mathrm{~K}$ excess silica precipitates almost instantaneously (e.g. Hemley 1981). 
For a fracture zone to be an effective means of focusing fluid, fluid pressures must be below lithostatic, and would probably be very nearly hydrostatic. For this reason a hydrostatic fluid pressures were used in all computations, as seen in Fig 2, the effect of varying fluid pressures between the lithostatic and hydrostatic limits is relatively minor provided the pressure gradient is uniform; this effect becomes even less important for cooler geotherms. In reality it is likely that within the collection region fluid pressure outside of the fracture zone is closer to lithostatic. In this case the fluid will undergo pressure throttling during focusing. Such a throttling effect could cause a massive increase in the amount of quartz precipitated at the base of the fracture zone but would not appreciably change amount of silica transported within the upper portions of the fracture zone. Pressure throttling is unlikely to be a significant factor during dispersion for two reasons (i) dispersion will occur when the fracture zone passes through relatively permeable rocks and in such a regime it would be difficult to maintain large pressure gradients; and (ii) at lower temperatures the change in solubility even due to a lithostatic-hydrostatic fluid pressure drop is unimportant (Fig 2, also Connolly \& Thompson 1989).

\subsection{Regional Focusing Model Results: Thermal Effects}

For a given geometry and focusing region width, the major sources of variation in the models are time and flow rate. Figs 3 shows the effect of time for models in which the regional flux is two orders of magnitude greater than the expected maximum $\mathrm{q}^{*}$. For both geometries, the general form of the thermal anomaly associated with the fracture zone develops by ca $25 \mathrm{ka}$. With additional time, the volume of thermally perturbed rocks increases and temperatures increase slightly; but, by $200 \mathrm{ka}$ the rate of temperature change slows substantially. In both models, the temperature perturbations are small in comparison to those reported by Chamberlain \& Rumble (1988), and notably more so for the planar fracture model. Indeed, the temperature anomaly generated for the pipe model is more than four times that obtained for a similar focusing factors and background fluxes in the models presented by Brady (1989) and Hoisch (1991). This would seem to contradict the intuitive expectation that conductive heat loss from a radially symmetric fracture system should be greater 
than for a planar geometry (Brady 1989); however, for a given focusing region width, radial focusing results in higher total fluxes, which is evidently a more important factor for the length scales considered here. The relatively rapid dispersion of heat and fluid flux for the radially symmetric model also causes the associated thermal anomaly to diminish more rapidly away from the vertical portion of the fracture zone.

Development of the thermal anomaly following the onset of fluid channeling can be seen more clearly in the temperature profiles along the pipe fracture zone axis (Fig 4). Early in the model evolution an isothermal region develops almost instantaneously at the base of the fracture zone. Above this region the thermal gradient within the fracture zone is constant and identical to the unperturbed geothermal gradient. This behavior reflects the fact that the down-temperature fluid flow must create a finite positive thermal anomaly. However, the consequent reduction in the thermal gradient increases the efficiency of heat convection by the fluid, so that the magnitude of thermal anomaly relative to the normal gradient will increase upwards. Provided vertical heat convection dominates over conduction, as is true for the flow rates chosen here, the flow will approach the isothermal limit. This isothermal region terminates when lateral heat conduction becomes comparable to the heat convection up the fracture zone for the initial geothermal gradient, i.e.:

$$
\mathrm{QC}_{\mathrm{f}} \frac{\mathrm{dT}}{\mathrm{dy}} \approx 2(1-\mathrm{p}+\mathrm{p} \pi \mathrm{w}) \mathrm{k} \frac{\mathrm{dT}}{\mathrm{dr}}
$$

thereafter flow occurs with the initial geothermal gradient, mimicking the models of Brady (1989) and Hoisch (1991). In the absence of perturbations to the conductive heat flow from the ends of the fracture zone, or from adjacent fractures, Eq 14 can be used to estimate the position at which the transition from isothermal flow to flow with the initial thermal gradient occurs in the steady state limit. For example, taking the planar fracture model with $\mathrm{Q}=0.63 \times 10^{-3} \mathrm{~kg} / \mathrm{m}$-s the total heat convection is $83 \mathrm{~J} / \mathrm{m}$-s for a vertical thermal gradient of $33 \mathrm{~K} / \mathrm{km}$, the lateral gradient necessary to accommodate this is then $(83 \mathrm{~J} / \mathrm{m}-\mathrm{s}) / 2 / \mathrm{k}=18 \mathrm{~K} / \mathrm{km}$. Assuming the lateral gradient away from the fracture zone is linear, then the isothermal flow would occur over a distance of ca $500 \mathrm{~m}$ above the fracture zone, in excellent agreement with the model illustrated in Fig 3. The model results show 
that this quasi-steady state develops long before the effect of dispersion becomes important $(\mathrm{t} \leq 25$ ka, Fig 4).

Dispersion of the fluid results in a second region of nearly isothermal flow, which develops because the rate of heat convection into the dispersion zone overwhelms the capacity of the rock to conduct heat away, i.e., thermal throttling. This results in an isothermal shock front that propagates upward into the dispersion region. As this front advances, its area increases, but the total rate of heat convection remains constant, reducing the velocity of the front. Consequently fluid dispersion results in a heating effect similar to that from a two dimensional heat source that expands and migrates upwards into the dispersion region. With time, the thermal anomaly within the dispersion region alters the nature of the heat flow within the fracture zone and perturbs the thermal gradient and quasi-steady state conditions attained earlier in the lower portions of the fracture zone. This in turn increases the ability of the fluid to transport heat and mass into the dispersion region, but this effect is countered by the increase in the volume of material that must be heated as the region of isothermal conditions broadens. In Fig 4 it can be seen that the increase in the temperature anomaly is about $10 \mathrm{~K}$ with a doubling of time, thus to achieve an anomaly of $150 \mathrm{~K}$ would require an additional time of at least 1.2 Ma. As discussed below it is unlikely fracture flow could be maintained on such time scales because of silica precipitation.

The effect of an order of magnitude reduction in the fracture zone width increases the temperature anomaly for the pipe model by $<20 \mathrm{~K}$ (Fig 4). This suggests that for fluid flow confined to fracture zones of $2 \mathrm{w}<500 \mathrm{~m}$, the critical parameter is the total flow rate rather than flux. This can be justified given that the time scale for heat conduction for such widths $\left(\tau=\frac{2 w^{2}}{\kappa}\right)$ is on the order of hundreds of years, much less than that necessary for the development of a significant thermal anomaly by confined fluid flow. Despite the extraordinarily high regional flux used for the calculations, the maximum thermal anomaly is only $110 \mathrm{~K}$ in the dispersion region (Fig 3), well below that necessary to explain the observations of Chamberlain \& Rumble (1989). Fig 5 shows that the effect of reducing this flux to more plausible values is to make the thermal perturbation imperceptible as $q \rightarrow$ $10 \mathrm{q}^{*}$. Thus, from Fig 5 it can be concluded that flow rates must exceed $0.1 \mathrm{~kg} / \mathrm{s}$ to produce a 
significant thermal effect for the pipe model (for the crack model the critical flow rate is ca $0.1 \mathrm{~g} / \mathrm{s}$ m). For the model geometries shown, these flow rates correspond to thermal Peclet numbers for one-dimensional flow of order one, reflecting the relative importance of vertical heat flow.

\subsection{Regional Focusing Model Results: Silica Transport}

Earlier modeling (e.g., Yardley 1986, Connolly \& Thompson 1989) has shown that the amount of quartz precipitated by pervasive, one-pass, fluid flow is inadequate to explain the quartz-veining in metamorphic rocks. As an alternative, Yardley (1986) suggested that silica transport by vertical, near-isothermal, fracture-controlled movement of relatively hot fluids into cooler overlying rocks could be responsible for quartz vein formation. However, the temperature profiles in Figs $3 \& 4$ demonstrate that extreme conditions are necessary to perturb the geothermal gradient within the fracture zone. Even when such conditions are realized, the models suggest that the geothermal gradient is unlikely to be reduced by more than $15 \mathrm{~K} / \mathrm{km}$ except in the uppermost portion of the fracture zone

(Fig 4). Any reduction in the geothermal gradient must increase the amount of silica transported by the fluid into the region where the fluid is finally dispersed and cooled. Thus the amount of silica precipitated in the dispersion regions for the models (Fig 6) is increased relative to that which would be precipitated by unfocused pervasive fluid movement. Because the change in quartz solubility with temperature is sensitive to the absolute temperature (Fig 2), this increase is minor in comparison to the amounts of quartz precipitated within the fracture zone and focusing region. Furthermore, the rapid cooling associated with dispersion is such an effective a means of precipitating quartz, that the amount quartz veining that can be produced by such processes decreases drastically away from the fracture zone. The amounts of silica precipitated within the fracture zone are orders of magnitude greater than that necessary to fill any single fracture capable of accommodating the focused fluid flow. This suggests that, if such systems do exist, then they must be zones of active deformation and fracturing. 


\section{Forced Advection Above a Cooling Pluton}

Granitic plutons are usually viewed as the heat engines responsible for driving free-convection, but they may also act as a source of intense, though ephemeral, fluid fluxes where free-convection is not possible. This section presents models constructed to examine the magnitude and scale of the effects that might arise from vertical channeling, and subsequent dispersion, of such fluids. At the outset, however, there are two reasons that it seems this is an improbable mechanism for generating the hotspots described by Chamberlain \& Rumble (1988): (i) lower crustal plutons are unlikely to be generated by wet solidus melting (e.g. Wyllie 1977), and therefore if they release large amounts of water, then the fluid will be released within 50-100 of the granite solidus (i.e., at temperatures too low, 923-1023 K, to form the hotspots); and (ii) to isolate advective heat effects, a plutonic fluid source would have to crystallize at depths of $5-10 \mathrm{~km}$ below the hotspot, which implies a cooler geotherm $(15-20 \mathrm{~K} / \mathrm{km})$ than suggested by Chamberlain \& Rumble's (1988) observations.

\subsection{Model for Crystallization of a Granitic Pluton}

A granitic (tonalite) pluton is assumed to be emplaced instantaneously at a depth of $20 \mathrm{~km}$ in rocks with an initial geotherm of $16 \mathrm{~K} / \mathrm{km}$. At emplacement the magma consists of $45 \mathrm{wt} \%$ melt phase with a water-content of $6.7 \mathrm{wt} \%$, at a temperature of $1013 \mathrm{~K}\left(\mathrm{~T}_{0}\right)$. The melt becomes watersaturated at $973 \mathrm{~K}\left(\mathrm{~T}_{1}\right)$, and releases water linearly with falling temperature to $923 \mathrm{~K}\left(\mathrm{~T}_{2}\right)$, at which point the melt is completely crystallized. Latent heat of crystallization (L, Table 1) is accounted for by expressing the specific heat of the magma as (Price \& Slack 1954):

$$
\mathrm{C}_{\mathrm{m}}{ }^{\prime}=\mathrm{C}_{\mathrm{rx}}+\frac{\mathrm{X}_{\mathrm{m}} \mathrm{L}}{\mathrm{T}_{0}-\mathrm{T}_{2}}
$$

where $X_{m}$ is the initial melt fraction. The enthalpic effect of fluid exsolution is taken to be nil (Clemens \& Navrotsky 1989). Heat loss due to removal of the fluid phase is approximated by a further adjustment to the melt specific heat:

$$
\mathrm{C}_{\mathrm{m}}{ }^{\prime \prime}=\mathrm{C}_{\mathrm{m}}{ }^{\prime}+\mathrm{X}_{\mathrm{w}} \mathrm{X}_{\mathrm{m}}\left(\mathrm{C}_{\mathrm{f}} \rho_{\mathrm{f}}-\mathrm{C}_{\mathrm{m}}{ }^{\prime}\right) \frac{\mathrm{T}_{1}+\mathrm{T}_{2}}{2\left(\mathrm{~T}_{2}-\mathrm{T}_{1}\right)} \quad \mathrm{T}<\mathrm{T}_{1}
$$


where $X_{w}$ is the initial water fraction of the melt.

The fluid is assumed to be released at the base of a fracture zone which migrates downward as the melt crystallizes. Both pipe and crack model geometries were solved using boundary conditions and methods as described for the fluid focusing models. Non-steady state fluid flux terms $(\nabla \mathrm{q})$ and free-convection of the magma were not considered. The crack models were done in 3-dimensional space to permit a finite fracture zone length.

\subsection{Cooling Pluton Model Results}

Model results for a spherical pluton of $5 \mathrm{~km}$ radius and pipe fracture zone of $900 \mathrm{~m}$ radius are summarized in Fig 7. These show that initial flow rates $(20-10 \mathrm{~kg} / \mathrm{s})$ generated by crystallization of a granitic pluton vastly exceed the rates necessary to overwhelm conductive heat transfer and generate advective heat anomalies. Once the initial thermal shock of emplacement has passed, fluid production rates drop in a roughly geometric progression with time so that the largest temperature anomaly in the dispersion region (ca $200 \mathrm{~K}$ ) occurs essentially instantaneously with emplacement. For the relatively large pluton dimension chosen here, free-convection within the pluton might result in lower fluid production rates. However, calculations done for a smaller pluton, of $3 \mathrm{~km}$ radius, yield comparable thermal effects and fluid production rates (an average of $13 \mathrm{~kg} / \mathrm{s}$ over $25 \mathrm{ka}$ ). Indeed it can be expected that the likelihood of preserving advective heat effects in metamorphic rocks will be larger with smaller plutons, because the conductive heat anomaly will be small.

For a $0.5 \times 5.5 \mathrm{~km}$ planar fracture zone, all other model factors being identical to those for the calculation illustrated in Fig 7, the magnitude of the advective heat effect is substantially smaller (Fig 8). Consequently for this geometry, the maximum temperatures achieved occur late in the model history and are associated with conductive heat transfer.

The geothermal gradients in the pluton models are less extreme than those required for the extraordinarily high temperatures of the metamorphic reaction in the regional fluid focusing models presented earlier. Despite this, the most extensive silica precipitation occurs at depths where the confined flow originates rather than where it is dispersed. Because of the greater reduction in the 
geothermal gradient in the pipe model, the distribution of quartz is more uniform, but nonetheless unimpressive.

\section{SUMMARY AND DISCUSSION}

The models for focusing of regionally generated metamorphic fluids presented here differ from those of Brady (1989) and Hoisch (1991) in that collection and dispersion of the fluid and radially symmetric flow have been considered in detail. Radially symmetric flow is arguably a more appropriate model for the formation of phenomena such as the metamorphic hotspots described by Chamberlain \& Rumble (1988). Likewise dispersal of fracture confined fluid flow would be necessary to form pervasive quartz veins within the hotspots, and, more generally, to permit fluid-rock interaction. Both factors are shown here to substantially magnify the thermal effects of focused fluid flow, but the computed temperature anomalies are only significant if flow rate approaches $0.1 \mathrm{~kg} / \mathrm{s}$ (pipe flow) or $0.1 \mathrm{~g} / \mathrm{m}$-s (crack flow) on time scales on the order of $10^{4}$ a. Given that regional metamorphic fluxes are estimated to be on the order of $10^{-9} \mathrm{~kg} / \mathrm{m}^{2}-\mathrm{s}$, radial focusing on a scale of 5-15 km would be necessary to generate such flow rates.

A fundamental limitation of such modeling is that it presumes the metamorphic process is continuous, but the lifetime of a large fracture zone is likely to be short in comparison to crustal metamorphic time scales. Consequently, hydrothermal effects such as those observed by Chamberlain \& Rumble (1988) may reflect periods of anomalously high fluid production, such as those which result from unstable systems (e.g., Yardley \& Lloyd 1995). The suggestion that lower crustal metamorphic reactions generate fluid pulses (Connolly \& Ko 1995), in which fluxes may be 50 times larger than steady state fluxes, is a possible mechanism for reducing the radial focusing distance to as little as $2 \mathrm{~km}$. Even so, lateral focusing on this scale seems improbable as it would require maintenance of large lateral pressure gradients and connected porosity at conditions where rocks are likely to deform rapidly, but this remains to be demonstrated. In contrast, the flow rates required to create detectable thermal effects are easily within the range that can be generated by the crystallization of mid-level granitic plutons. Conductive cooling of a granitic pluton with a radius of 3-5 $\mathrm{km}$ can 
produce fluid at rates of $10-20 \mathrm{~kg} / \mathrm{s}$ for periods of 10-50 ka. Vertical channeling of this fluid, even in a relatively broad fracture zone of ca $1 \mathrm{~km}$ radius, over a distance of $10 \mathrm{~km}$, may produce temperature anomalies of $>200 \mathrm{~K}$. These effects and the predicted quartz-vein modes are similar to those observed in stock-works (e.g., Mikucki \& Heinrich 1993); however granitic plutons are unlikely to produce water-rich fluid at temperatures above $873 \mathrm{~K}$ and thus cannot explain temperatures of this magnitude in Chamberlain \& Rumble's (1988) metamorphic hotspots. The present modeling demonstrates that large-scale channelized vertical flow is capable of creating significant temperature anomalies, but the origin of Chamberlain \& Rumble's (1988) hotspots, the best defined examples of anomalies generated by heat convection, remains enigmatic.

The ability of a hydrothermal fluid to transport a saturated solute such as silica is dependent both on the thermal gradient and, roughly, the log of the absolute temperature; however the ability of the fluid to transport heat is virtually independent of the absolute temperature. Consequently, even if fluid fluxes can be attained that are adequate to produce advective anomalies, there is no reason to expect that the mass and heat anomalies will coincide in either time or space. This is demonstrated by the modeling here which shows that while extensive silicification occurs in the lower portion of the fracture zone, little occurs when the fluid is dispersed after passing through the region where the thermal effects are most pronounced. This implies that such fracture systems would be choked at depth by silicification in relatively short time spans $(<25 \mathrm{ka})$ unless the fracturing is a continuous process. This effect would be accentuated by pressure throttling, which is most likely to be important when fluid enters the fracture zone. Thus it appears necessary to invoke free-convection or pressure solution to explain pervasive quartz veins in regionally metamorphosed rocks. This is in accord with many recent studies that have ascribed vein formation to local phenomena, rather than advective transport (e.g., Oliver et al 1990, Yardley \& Botrell 1992, Fisher \& Brantley 1992). In contrast, in sedimentary basins (Pederson et al., this volume) and subduction zones (Manning this volume) fluid fluxes, and kinetic effects, may be large enough to allow significant silica transport. 


\section{Acknowledgements}

I am grateful to: M. N. Ozisik for introducing me to the numeric techniques used in this study; M. Casey for suggesting the dispersion model; and M. J. Bickle, B. W. D. Yardley, J. Ridley, and A. B. Thompson for helpful reviews and/or discussion. This paper was mostly written in 1989, forgotten, and then hurriedly finished and revised for this volume, in consequence the analysis is less complete than it should be, in particular with regard to scaling.

\section{APPENDIX: NUMERIC SOLUTION OF THE HEAT FLOW EQUATION}

The heat flow equation, Eq 12, was solved numerically using the a Crank-Nicolson weighted finite difference method, second order accurate centered differencing was used for the Laplacians, and upwind second order accurate differencing for gradients. In most calculations, numeric grid generation (Thompson 1984) was used to enhance the accuracy of the solutions by permitting spatial resolution on a cm-scale in the vicinity of the fracture zones. By this technique the computational spatial domain described by a regular spaced grid in the variables $\zeta(\mathrm{r}, \mathrm{y})$ and $\eta(\mathrm{r}, \mathrm{y})$ which are non-linear functions of the true spatial coordinates $r$ and $y$. This method reduces the error associated with conventional techniques for irregular grid spacing. The transformation between the computational and real spatial domains is defined such that:

$$
\begin{aligned}
& \frac{\partial \mathrm{T}}{\partial \mathrm{r}}=\frac{1}{\mathrm{~J}}\left[\frac{\partial \mathrm{y}}{\partial \eta} \frac{\partial \mathrm{T}}{\partial \zeta}-\frac{\partial \mathrm{y}}{\partial \zeta} \frac{\partial \mathrm{T}}{\partial \eta}\right] \\
& \frac{\partial \mathrm{T}}{\partial \mathrm{y}}=\frac{1}{\mathrm{~J}}\left[-\frac{\partial \mathrm{x}}{\partial \eta} \frac{\partial \mathrm{T}}{\partial \zeta}+\frac{\partial \mathrm{x}}{\partial \zeta} \frac{\partial \mathrm{T}}{\partial \eta}\right]
\end{aligned}
$$

and

$$
\nabla^{2} \mathrm{~T}=\frac{1}{\mathrm{~J}^{2}}\left[\alpha \frac{\partial^{2} \mathrm{~T}}{\partial \zeta^{2}}-2 \beta \frac{\partial}{\partial \eta}\left[\frac{\partial \mathrm{T}}{\partial \zeta}\right]+\gamma \frac{\partial^{2} \mathrm{~T}}{\partial \eta^{2}}\right]+\left[\nabla^{2} \zeta \frac{\partial \mathrm{T}}{\partial \zeta}+\nabla^{2} \eta \frac{\partial \mathrm{T}}{\partial \eta}\right]
$$

where

$$
\alpha=\left[\frac{\partial \mathrm{x}}{\partial \eta}\right]^{2}+\left[\frac{\partial \mathrm{y}}{\partial \eta}\right]^{2}, \quad \beta=\frac{\partial \mathrm{x}}{\partial \zeta} \frac{\partial \mathrm{x}}{\partial \eta}+\frac{\partial \mathrm{y}}{\partial \zeta} \frac{\partial \mathrm{y}}{\partial \eta}, \quad \gamma=\left[\frac{\partial \mathrm{x}}{\partial \zeta}\right]^{2}+\left[\frac{\partial \mathrm{y}}{\partial \zeta}\right]^{2}
$$




$$
\mathrm{J}=\frac{\partial \mathrm{x}}{\partial \zeta} \frac{\partial \mathrm{y}}{\partial \eta}-\frac{\partial \mathrm{x}}{\partial \eta} \frac{\partial \mathrm{y}}{\partial \zeta}
$$

The metrics of the transformation are then determined from simultaneous solution of the finite difference approximation to the equations:

$$
\begin{aligned}
& \nabla^{2} \zeta=\mathrm{P}(\zeta, \eta) \\
& \nabla^{2} \eta=\mathrm{Q}(\zeta, \eta)
\end{aligned}
$$

where $\mathrm{P}(\zeta, \eta)$ and $\mathrm{Q}(\zeta, \eta)$ are arbitrarily specified grid control functions used to attract the real grid points toward selected locations in the transformed coordinate space.

\section{REFERENCES}

Bickle MJ, McKenzie D (1987) The transport of heat and matter by fluids during metamorphism. Contr Mineral Petrol 95:384-392

Bjorlykke K, Mo A, Palm E (1988) Modelling of thermal convection in sedimentary basins and its relevance to diagenetic reactions. Marine Petroleum Geol 5:338-351.

Brady J (1989) The role of volatiles in the thermal history of metamorphic terranes. J Petrol 29:1187-1213

Chamberlain CP, Rumble D (1988) Thermal anomalies in a regional metamorphic terrain: an isotopic study of the role of fluids. J Petrol 29:1215-1232

Clemens JC, Navrotsky A (1987) Mixing properties of $\mathrm{NaAlSi}_{3} \mathrm{O}_{8}-\mathrm{H}_{2} \mathrm{O}$ melt: new calorimetric data and some geologic implications. J Geol 95:173-186

Connolly JAD, Thompson AB (1989) Fluid and enthalpy production during regional metamorphism. Contrib Mineral Petrol 102:346-366 
Connolly JAD, Ko S-C (1995) Development of excess fluid pressure during dehydration of the lower crust. Terra Abstracts 7:312

England PC, Thompson AB (1984) Pressure-temperature-time paths of regional metamorphism, I, Heat transfer during the evolution of regions of thickened crust. J Petrol 25:894-928

Etheridge MA, Wall VA, Vernon RH (1983) The role of the fluid phase during regional metamorphism and deformation. J Metamorph Petrol 83:205-226

Ferry JM (1987) Metamorphic hydrology at $13 \mathrm{~km}$ depth and 400-550\&x'a1.C. American Mineralogist $72: 39-58$

Fisher DM, Brantley SL (1992) Models of quartz overgrowth and vein formation: deformation and episodic fluid flow in an ancient subduction zone. J Geophys Research 97:20043-20061.

Fyfe WS, Price NJm Thompson AB (1978) Fluids in the earth's crust. Elsevier, 333 p.

Ganguly J, Singh RN, Ramana DV (1995) Thermal perturbation during Charnockitization and granulite facies metamorphism in southern India. J Metamorph Geol 13:419-430

Hemley JJ, Montoya JW, Marienko JW, Luce RW (1980) Equilibria in the system $\mathrm{Al}_{2} \mathrm{O}_{3}-\mathrm{SiO}_{2}-\mathrm{H}_{2} \mathrm{O}$ and some general implications for alteration mineralization processes. Econ Geol 75:210-228

Hoisch TD (1991) The thermal effects of pervasive and channelized fluid flow in the deep crust. J Geol 99:69-80

Jamtveit B, Bucher-Nurminen K, Austrheim H (1990) Fluid controlled eclogitization of granulites in 
deep shear zones, Bergen Arcs, western Norway. Contr Mineral Petrol 104:184-193

Manning CE (1994) The solubility of quartz in $\mathrm{H}_{2} \mathrm{O}$ in the lower crust and upper mantle. Geochim Cosmochim Acta 58:4831-4839

Mickucki EJ, Heinrich CA (1993) Vein- and mine-scale wall-rock alteration and gold mineralisation in the Mount Charlotte deposit, Kalgoorlie, Western Australia. Australian Geol Surv Org Extended Abstracts 54:135-140

Norton D, Knapp R (1970) Transport phenomena in hydrothermal systems: nature of porosity. Am J Sci 277:913-936

Norton D, Knight (1977) Transport phenomena in hydrothermal systems: cooling plutons. Am J Sci 277:937-981

Oliver NHS, Cartwright I, Wall VJ, Golding SD (1993) The stable isotope signature of kilometrescale fracture dominated metamorphic fluid pathways, Mary Kathleen, Australia. J Metamorph Geol $11: 705-720$

Ozisik MN (1985) Heat Transfer, McGraw-Hill, NY.

Price RH, Slack MR (1954) The effect of latent heat on numerical solutions of the heat flow equation. Br J Appl Phys 5:285-287

Peacock SM (1989) Numerical constraints on rates of metamorphism, fluid production, and fluid flux during regional metamorphism. Geol Soc Am Bull 101:476-485 
Peacock SM (1987) Thermal effects of metamorphic fluids in subduction zones. GEOLOGY $15: 1057-1060$

Skelton ADL, Graham CM, Bickle MJ (1995) Lithological and structural controls on regional 3-D fluid flow patterns during greenschist facies metamorphism of the Dalradian of the SW Scottish Highlands. J Petrol 36:000-000

Thompson JF (1984) Grid generation techniques in computational fluid dynamics. AIAA J 22:15051523

Thompson PH (1989) Moderate overthickening of thinned sialic crust and the origin of granitic magmatism and regional metamorphism in low-P-high-T terranes. GEOLOGY 17:520-523

Walther JV, Orville PM (1982) Volatile production and transport in regional metamorphism. Contr Mineral Petrol 79:252-257

Wyllie PJ (1977) Crustal anatexis: an experimental review. Tectonophysics 43:41-71

Yardley BWD (1986) Fluid migration and veining in the Connemara Schists, Ireland. In: Walther JV, Wood BJ (eds) Fluid-Rock Interactions during Metamorphism. Springer, New York, pp 89-108

Yardley BWD, Bottrell SH (1992) Silica mobility and fluid movement during metamorphism of the Connemara schists, Ireland. J Metamorph Geol 10:453-464.

Yardley BWD, Lloyd GE (1995) Why metasomatic fronts are really sides. GEOLOGY 23:53-56 


\section{FIGURE CAPTIONS}

Fig 1 - Geometry of models for focusing and dispersion of metamorphic fluid. The pipe model has radial symmetry about the fracture zone axis, and the crack model has mirror symmetry perpendicular to the fracture plane.

Fig 2 - Initial model conditions. Vertical and horizontal flux components are shown for the crack model contoured in terms of the regional metamorphic flux q (Eqs $6 \&$ 7), flux components vary more strongly in the pipe model. Silica solubilities (at quartz saturation, Manning 1994) are shown at both lithostatic $\left(\rho_{\mathrm{rx}} \mathrm{g} \mathrm{y}\right)$ and hydrostatic $\left(\rho_{\mathrm{f}} \mathrm{g} \mathrm{y}\right)$ pressure.

Fig 3 - Temperature evolution as a function of time for a high regional fluid flux (10 $\left.\mathrm{q}^{*}\right)$.

Fig 4 - Differences between the temperature along the fracture zone axis and the unperturbed geotherm temperature for the pipe model as a function of time and fracture zone width. Model parameters are slightly different from those shown in Fig $3: \mathrm{Q}=1.2 \mathrm{~kg} / \mathrm{s}, \mathrm{q}=10 \mathrm{q}^{*}$, and focusing and dispersion region half-widths of 9 and $3 \mathrm{~km}$, respectively. Curves are labeled by time in ka; solid and dashed curves correspond to thermal anomalies for fracture zone widths of 500 and $50 \mathrm{~m}$, respectively. Isothermal flow is very nearly realized at the transition from confined to dispersed flow and in the lower portion of the fracture zone.

Fig 5 - Effect of variation in regional flux for the pipe model at $200 \mathrm{ka}$. To a good approximation variation in regional flux also can be used to simulate a change in the collection area $\left(\mathrm{W}_{\mathrm{f}}\right)$. From Eqs $9 \& 11$ flow rates for a focusing radius of $5 \mathrm{~km}$ and regional fluxes of $10 \mathrm{q}^{*}$ and $0.1 \mathrm{q}^{*}$, are equivalent to flow rates for focusing radii of 15 and $2.3 \mathrm{~km}$ with a regional flux of $\mathrm{q}^{*}$.

Fig 6 - Amount of quartz precipitated for pipe and crack models after 200 ka. For clarity, contours of quartz modes greater than 7 volume $\%$ are not shown for the pipe model, these modes reach a 
maximum of $\approx 60 \%$ near the base of the fracture zone and drop smoothly to 7 volume $\%$ at the base of the dispersion region. Horizontal scale is twice the vertical scale.

Fig 7 - Temperature evolution following emplacement of tonalitic pluton assuming water released during crystallization is focused into a $1.8 \mathrm{~km}$ wide pipe-like fracture zone and dispersed $10 \mathrm{~km}$ above the pluton. Portions of the pluton at temperatures above fluid saturation, at fluid saturation, and fully crystallized indicated by light, heavy, and intermediate shading. $\mathrm{X}$ is the fraction of water remaining in the melt phase.

Fig 8 - Temperature distribution $10 \mathrm{ka}$ after emplacement of tonalitic pluton assuming water released during crystallization is focused into a $0.5 \times 5.5 \mathrm{~km}$ planar fracture. Other parameters and labeling as in Fig 7.

Fig 9 - Distribution of quartz precipitated by forced convection through pipe and crack fracture zones above cooling plutons as in Figs $7 \&$ 8. Horizontal scale is thrice the vertical scale. 
TABLE 1. Frequently Used Symbols and Characteristic Values

\begin{tabular}{|c|c|c|c|}
\hline Symbol & Meaning & Units & Chracteristic Value \\
\hline $\mathrm{C}_{\mathrm{rx}}$ & rock specific heat & $\mathrm{J} / \mathrm{m}^{3}-\mathrm{K}$ & $2.5 \times 10^{6}$ \\
\hline $\mathrm{C}_{\mathrm{f}}$ & fluid heat capacity & $\mathrm{J} / \mathrm{kg}-\mathrm{K}$ & $4 \times 10^{3}$ \\
\hline$\hat{\mathrm{E}}$ & integrated catchment efficiency, planar symmetry & 0.636 & \\
\hline$\hat{\mathrm{E}}$ & integrated catchment efficiency, radial symmetry & 0.463 & \\
\hline $\mathrm{k}$ & thermal conductivity & $\mathrm{W} / \mathrm{m} / \mathrm{K}$ & 2.25 \\
\hline $\mathrm{L}$ & latent heat of melting & $\mathrm{J} / \mathrm{kg}$ & $2 \times 10^{5}$ \\
\hline q & unfocused fluid mass flux rate & $\mathrm{kg} / \mathrm{m}^{2}-\mathrm{s}$ & \\
\hline$q^{*}$ & expected maximum q & $\mathrm{kg} / \mathrm{m}^{2}-\mathrm{s}$ & $10^{-9}$ \\
\hline $\mathrm{p}$ & symmetry flag, planar symmetry & & 0 \\
\hline $\mathrm{p}$ & symmetry flag, radial symmetry & & 1 \\
\hline Q & fluid mass flow rate & $\mathrm{kg} / \mathrm{m}^{\mathrm{p}-1}-\mathrm{s}$ & \\
\hline $\mathrm{r}$ & horizontal distance coordinate & $\mathrm{km}$ & \\
\hline $\mathrm{t}$ & time & s, a, ka, Ma & \\
\hline $\mathrm{T}$ & temperature & $\mathrm{K}$ & \\
\hline $\mathrm{W}$ & half-width of focusing/dispersion region & $\mathrm{km}$ & 5 \\
\hline $\mathrm{w}$ & half-width of fracture zone & $\mathrm{km}$ & $0.025-1$ \\
\hline y & depth & $\mathrm{km}$ & \\
\hline$\kappa$ & thermal diffusivity & $\mathrm{m}^{2} / \mathrm{s}$ & $1.1 \times 10^{-6}$ \\
\hline$\rho_{\mathrm{f}}$ & fluid density & $\mathrm{kg} / \mathrm{m}^{3}$ & $0.7-0.9 \times 10^{3}$ \\
\hline$\rho_{\mathrm{rx}}$ & rock density & $\mathrm{kg} / \mathrm{m}^{3}$ & $2.8 \times 10^{3}$ \\
\hline
\end{tabular}


TABLE 1. Frequently Used Symbols and Characteristic Values

\begin{tabular}{llll} 
Symbol & Meaning & Units & Chracteristic Value \\
\hline $\mathrm{C}_{\mathrm{rx}}$ & rock specific heat & $\mathrm{J} / \mathrm{m}^{3} / \mathrm{K}$ & $2.5 \times 10^{6}$ \\
$\mathrm{C}_{\mathrm{f}}$ & fluid heat capacity & $\mathrm{J} / \mathrm{kg} / \mathrm{K}$ & $4 \times 10^{3}$ \\
$\hat{\mathrm{E}}$ & integrated catchment efficiency, planar symmetry & 0.636 & \\
$\hat{\mathrm{E}}$ & integrated catchment efficiency, radial symmetry & 0.636 & \\
$\mathrm{k}$ & thermal conductivity & $\mathrm{W} / \mathrm{m} / \mathrm{K}$ & 2.25 \\
$\mathrm{~L}$ & latent heat of melting & $\mathrm{J} / \mathrm{kg}$ & $2 \times 10^{5}$ \\
$\mathrm{q}$ & unfocused fluid mass flux rate & $\mathrm{kg} / \mathrm{m}^{2} / \mathrm{s}$ & \\
$\mathrm{q}^{*}$ & expected maximum q & $\mathrm{kg} / \mathrm{m}^{2} / \mathrm{s}$ & $10^{-9}$ \\
$\mathrm{p}$ & symmetry flag, planar symmetry & 0 & \\
$\mathrm{p}$ & symmetry flag, radial symmetry & 1 & \\
$\mathrm{Q}$ & fluid mass flow rate & $\mathrm{kg} / \mathrm{m}^{\mathrm{p}-1}-\mathrm{s}$ & \\
$\mathrm{r}$ & horizontal distance coordinate & $\mathrm{km}$ & \\
$\mathrm{t}$ & time & $\mathrm{s}, \mathrm{a}, \mathrm{ka}, \mathrm{Ma}$ & \\
$\mathrm{T}$ & temperature & $\mathrm{K}$ & \\
$\mathrm{W}$ & half-width of focusing/dispersion region & $\mathrm{km}$ & 5 \\
$\mathrm{w}$ & half-width of fracture zone & $\mathrm{km}$ & $0.025-1$ \\
$\mathrm{y}$ & depth & $\mathrm{km}$ & \\
$\kappa$ & thermal diffusivity & $\mathrm{m}^{2} / \mathrm{s}$ & $1.1 \times 10^{-6}$ \\
$\rho_{\mathrm{f}}$ & fluid density & $\mathrm{kg} / \mathrm{m}^{3}$ & $0.7-0.9 \times 10^{3}$ \\
$\rho_{\mathrm{rx}}$ & rock density & $\mathrm{kg} / \mathrm{m}^{3}$ & $2.8 \times 10^{3}$ \\
& & &
\end{tabular}


Connolly Figure 1

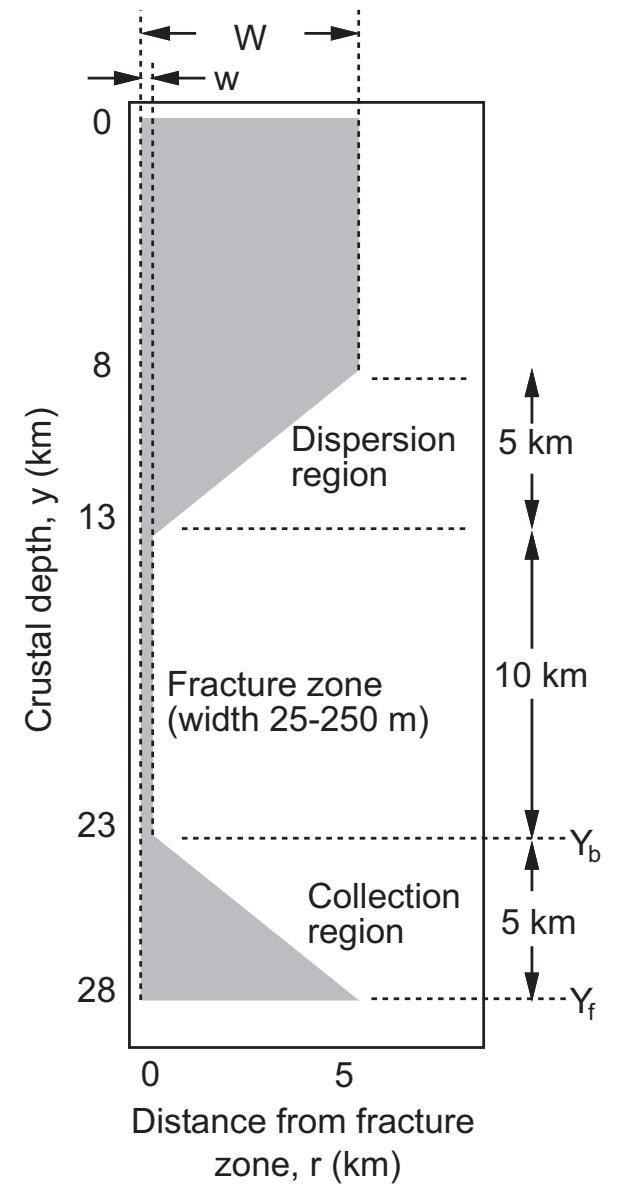


Connolly Figure 2
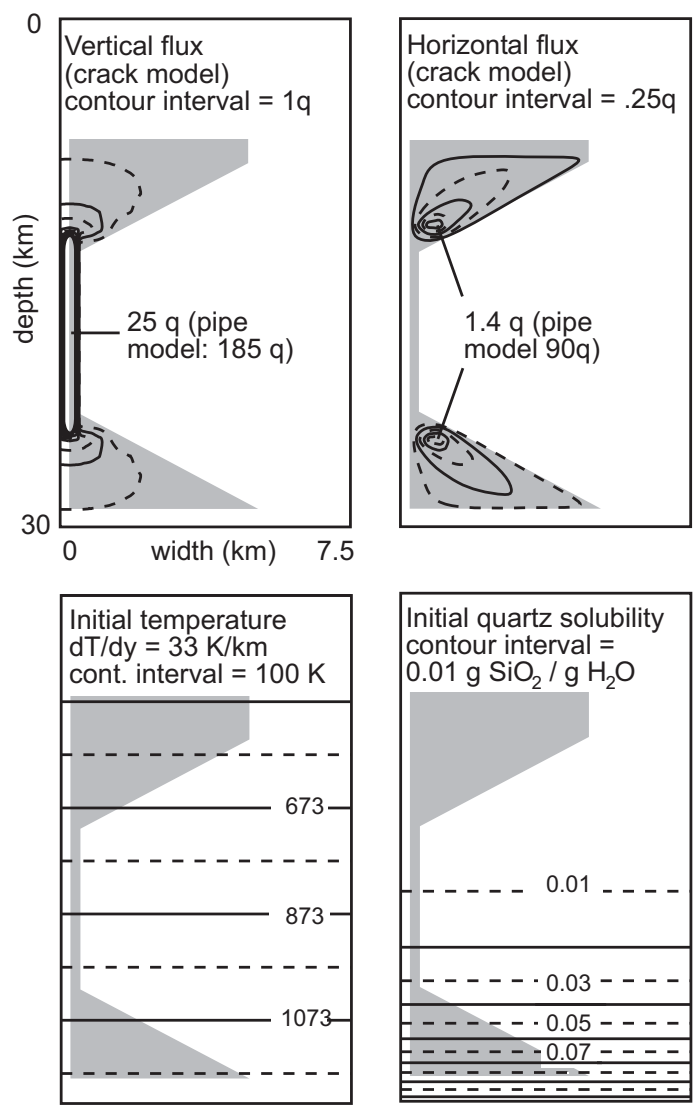

Initial quartz solubility contour interval $=$

$0.01 \mathrm{~g} \mathrm{SiO}_{2} / \mathrm{g} \mathrm{H}_{2} \mathrm{O}$

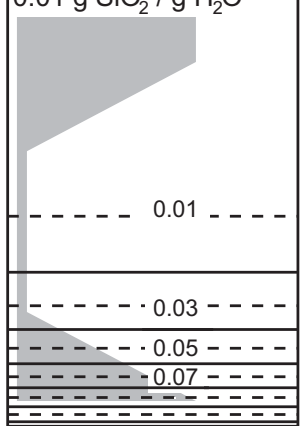


Connolly Figure 3.

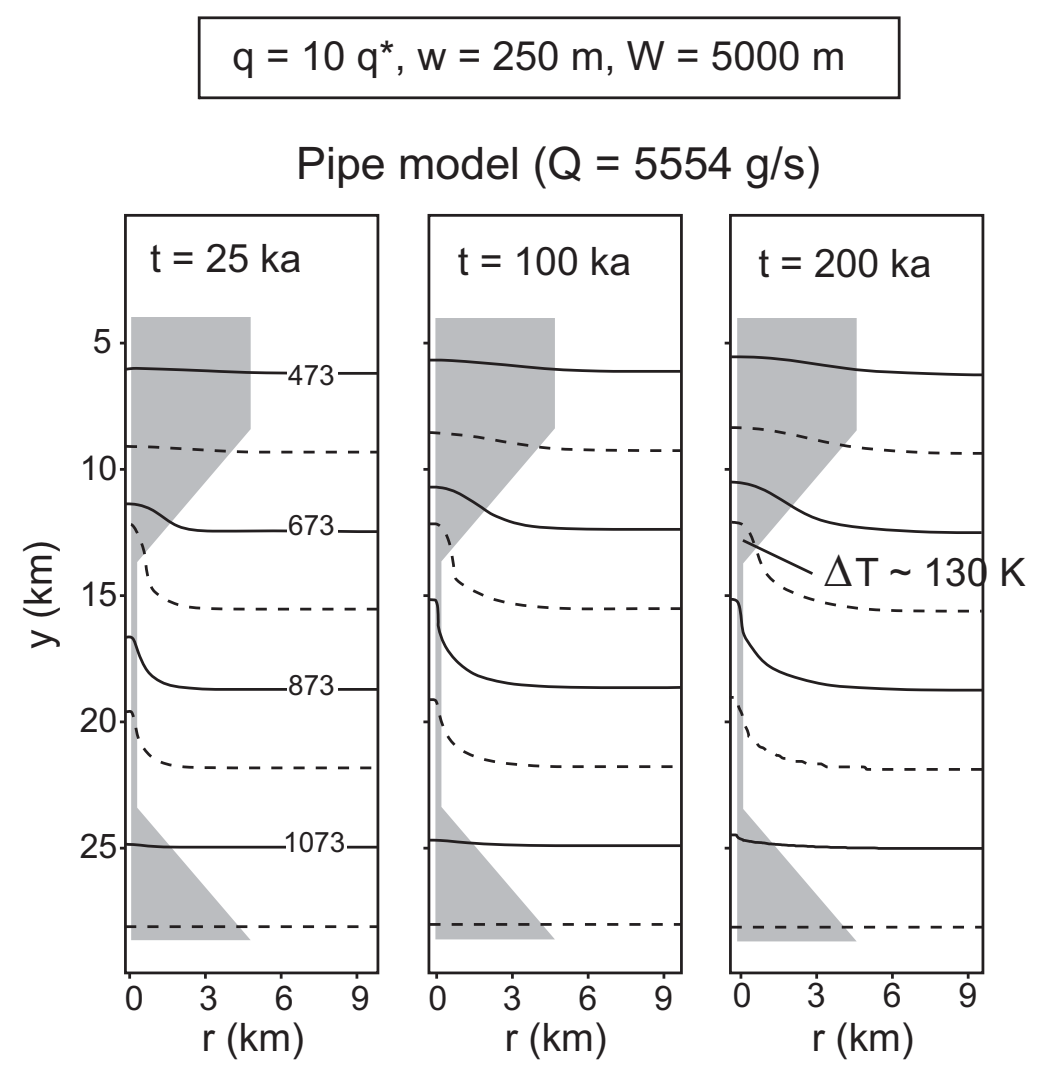

Crack model $(Q=0.63 \mathrm{~g} / \mathrm{m}-\mathrm{s})$

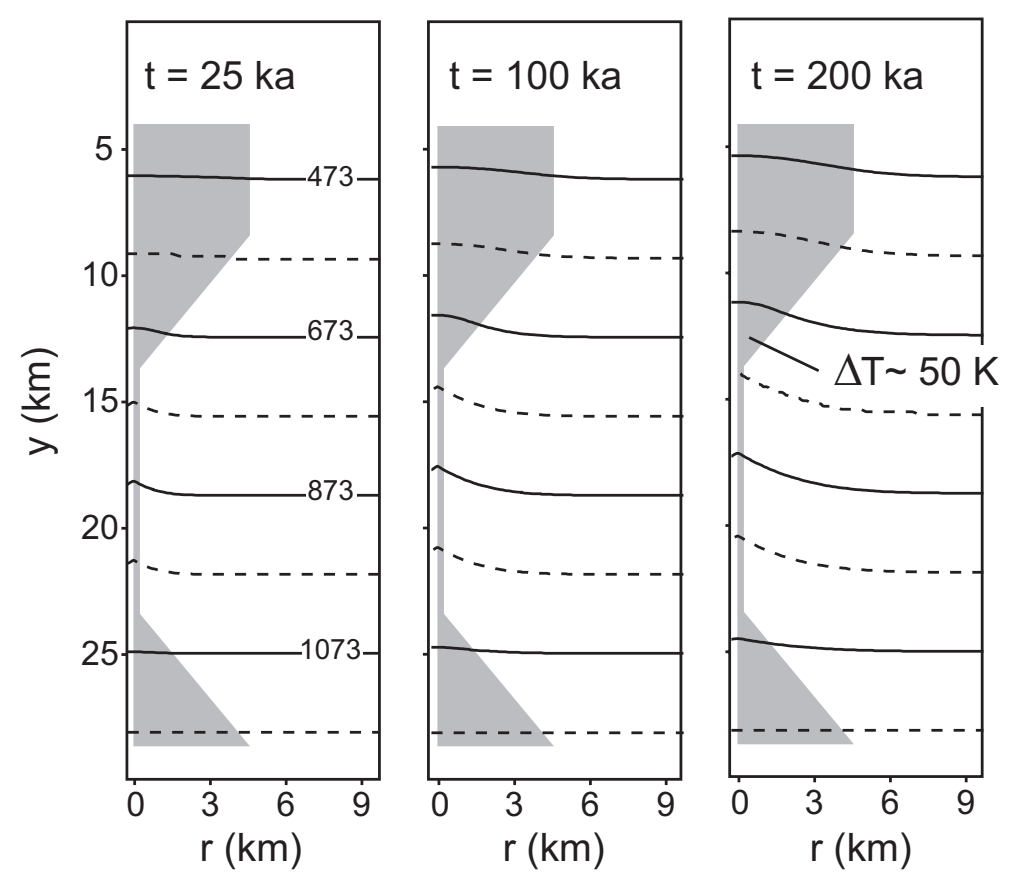


Connolly Figure 5

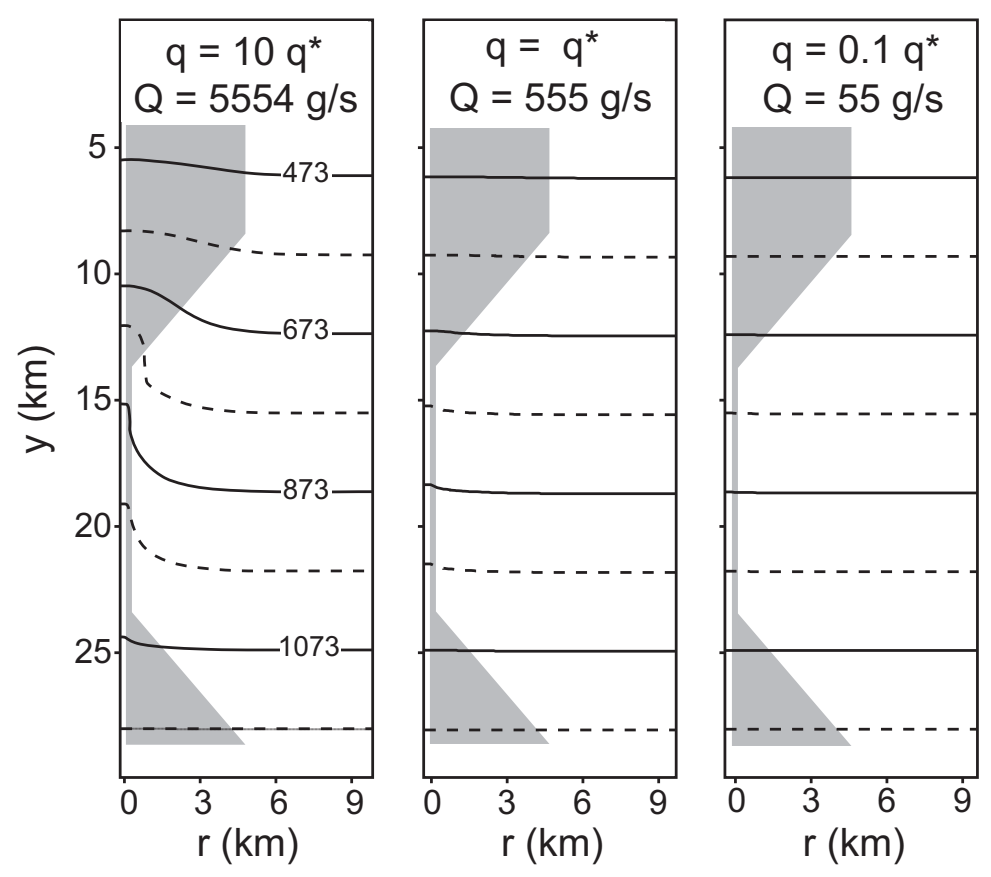


Connolly Figure 6

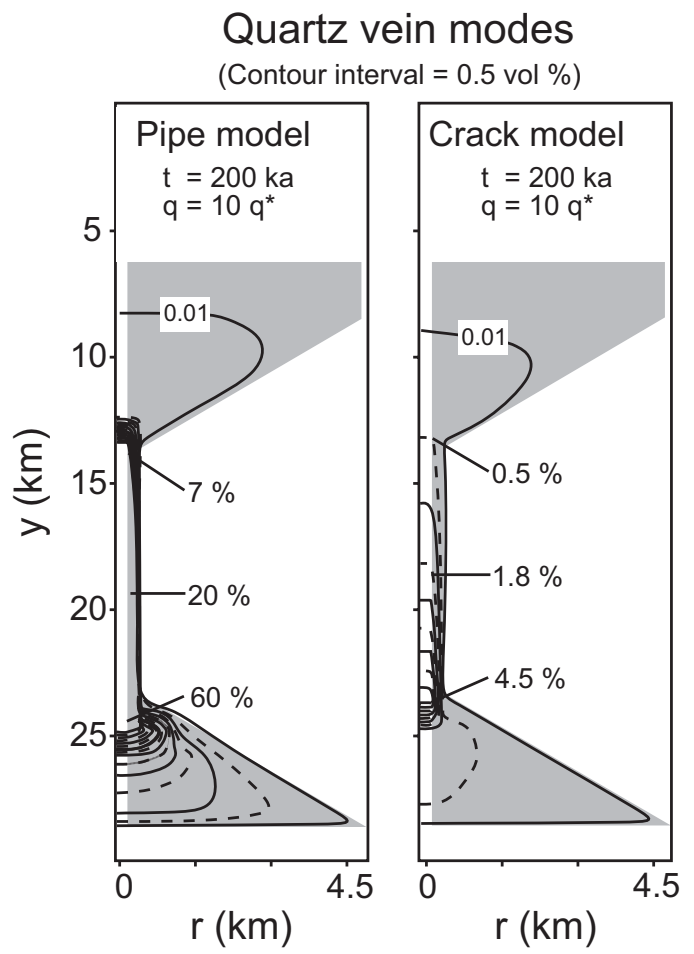

a. 5 
Connolly Figure 7

Pipe model temperatures above a cooling pluton

Pipe radius $=900 \mathrm{~m}$
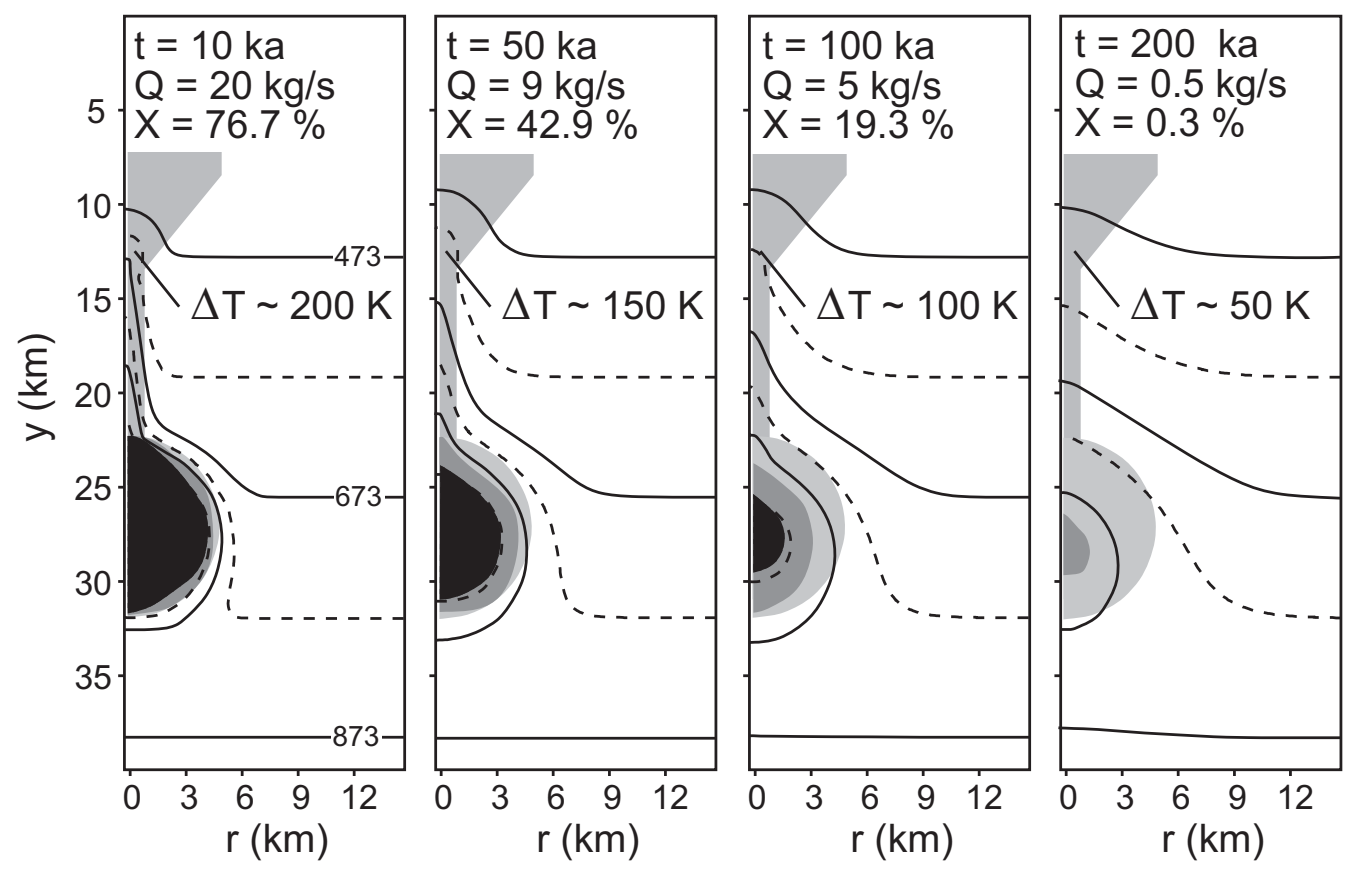
Connolly Figure 4

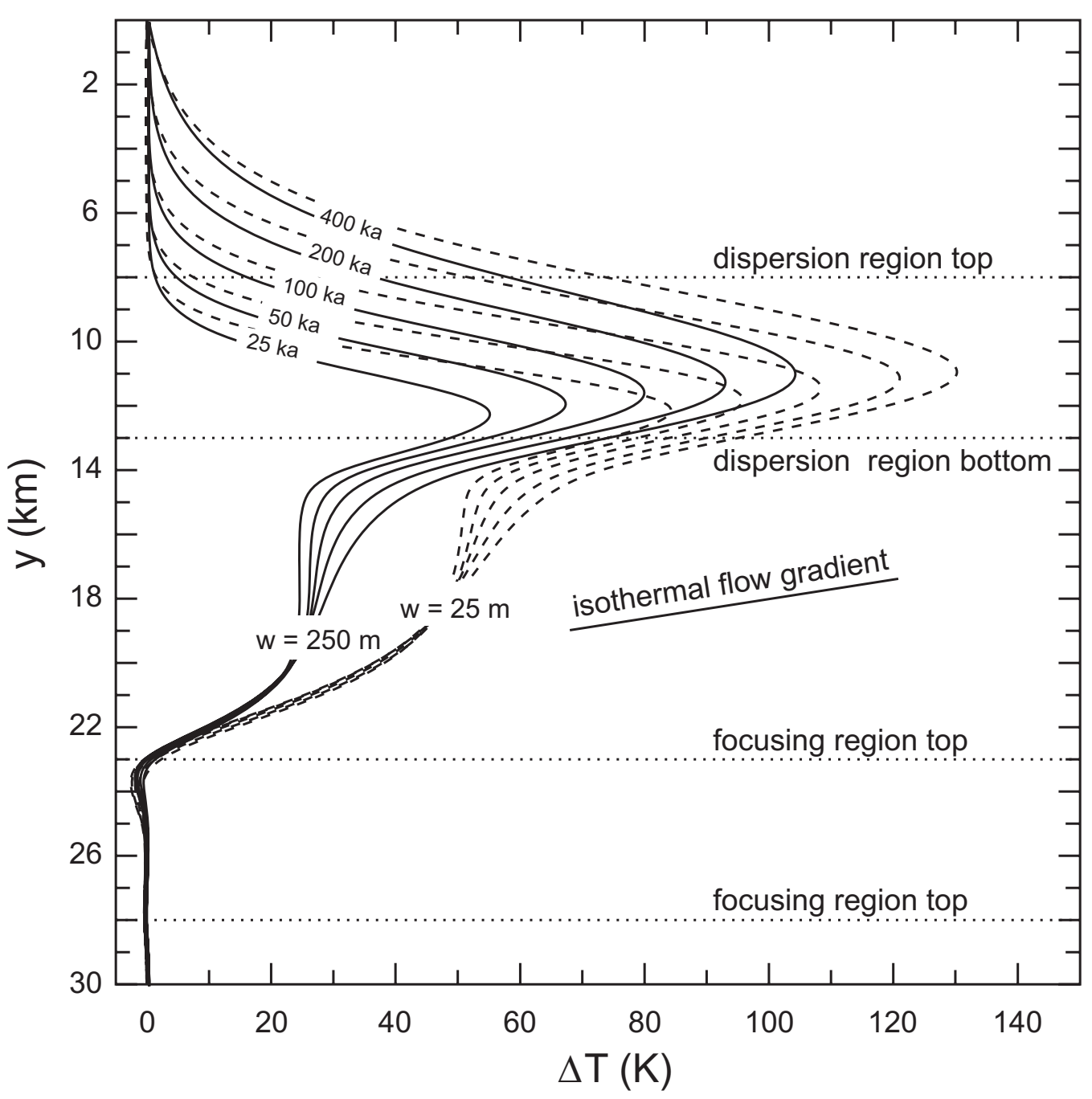


Connolly Figure 9

Quartz vein modes

(Contour interval 0.5 vol \%)
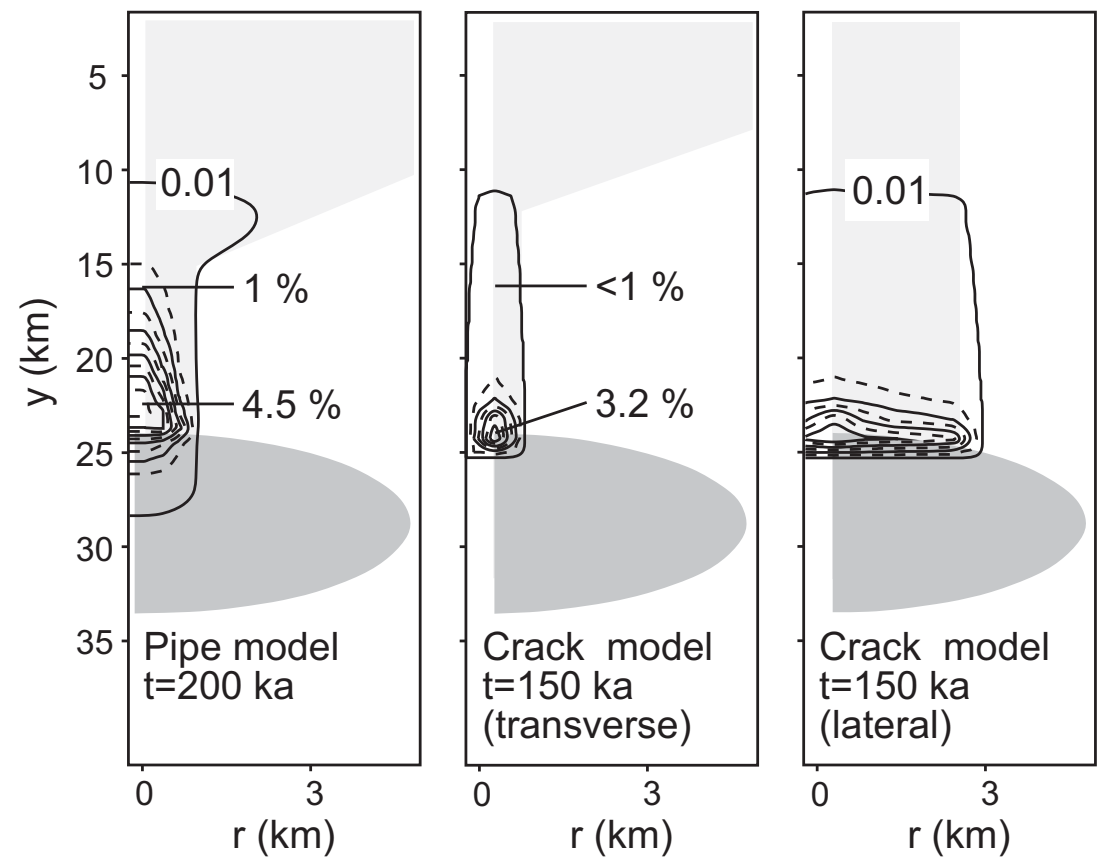

a.8 
Connolly Figure 8

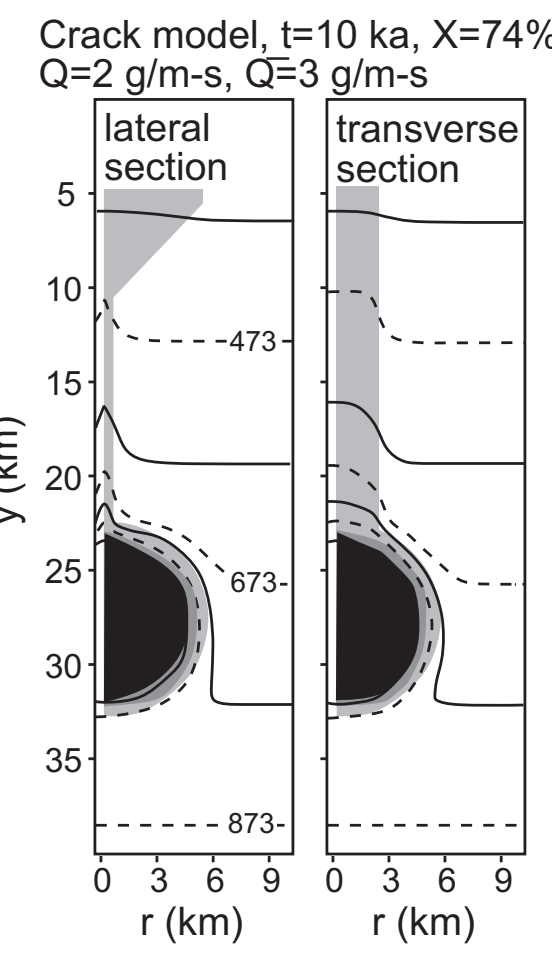

